Forthcoming in the Journal of Economic Theory

September 13, 2005

\title{
COMPETITIVE-SEARCH EQUILIBRIUM IN MONETARY ECONOMIES
}

\author{
Miquel Faig and Xiuhua Huangfu* \\ University of Toronto
}

Running title: Competitive Search and Money

${ }^{*}$ We are grateful for the comments by two anonymous referees, the Associate Editor, Randy Wright, and Guillaume Rocheteau, as well as for those made by the participants of the Summer Workshop at the Cleveland Fed in August 2004. We are also grateful for the financial support of SSHRC of Canada. The usual disclaimer applies. Corresponding author: Miquel Faig, 140 St. George Street, Suite 707, Toronto, Canada, M5S 3G6. E-mail: mfaig@chass.utoronto.ca. Phone: (416) 978-0308. Fax: (416) 978-5519. 


\begin{abstract}
Competitive search was recently introduced in monetary economics by Rocheteau and Wright (2005). We extend their work by eliminating the restriction that the fees market makers charge to enter a submarket must be either non-negative or identical for buyers and sellers. Without this restriction, buyers pay a positive fee to enter the submarket they visit and nothing else when they meet a seller. Sellers are remunerated by the market makers from the entry fees collected from the buyers. This trading arrangement allows buyers to perfectly predict their expenses, so the opportunity cost of holding idle money balances is eliminated.
\end{abstract}

Keywords: competitive search, monetary search.

JEL: E40 


\section{Introduction}

Competitive search (price posting with directed search) is an equilibrium concept that introduces price competition in an environment where trades take place in bilateral matches. This concept has been widely used in labor economics, and was recently introduced into monetary economics by Rocheteau and Wright in [4]. This comment to [4] seeks to clarify that competitive search has a property without counterpart in non-monetary economies. Namely, when money is the medium of exchange, competitive search tends to make payments predictable to avoid idle money balances.

There have been several formulations of competitive search. In [4], a large number of potential market makers organize trading centers referred to as submarkets, in which, the market makers post trading offers specifying the terms at which buyers and sellers must trade. Buyers and sellers can only find a trading partner by entering a submarket, once in there, they randomly match in pairs. The market makers can charge fees to buyers and sellers to enter their submarket and seek maximum profits, but competition among market makers drives their profits to zero and leads to ex-ante bilaterally efficient trading arrangements. ${ }^{1}$

We extend [4] by eliminating the restriction that the entry fees market makers charge must be either non-negative or identical for buyers and sellers. Without this restriction, equilibrium trading arrangements have the following property. As long as there is an opportunity cost of carrying money and matching is frictional, buyers pay a positive fee to enter the submarket they visit and nothing else when they meet a seller. Sellers are remunerated by the market makers from the entry fees collected from the buyers. This trading arrangement allows buyers to perfectly predict their expenses so that the opportunity cost of holding idle money balances is eliminated. ${ }^{2}$

\footnotetext{
${ }^{1}$ Equilibrium trading offers and market composition maximize the expected surplus of a buyer subject to the expected surplus of a seller and the constraints imposed by the environment.

${ }^{2}$ The role of market makers in this model is similar to the role played by banks in [1].
} 
To support our equilibrium, market makers must be present organizing the trading centers where buyers and sellers are matched in pairs and play an active role in the transfer of payments from buyers to sellers. In standard non-monetary economies, the presence of market makers is just an expositional device. In these economies, one can equivalently assume that submarkets are created by market makers, or that they are implicitly created by buyers or sellers posting the trading offers they commit to trade. In contrast, the market makers in our model play a fundamental role by allowing buyers to carry less money balances, ${ }^{3}$ which leads to welfare-improving allocations that otherwise would not be possible.

In summary, competitive search with submarkets organized by unrestricted market makers leads to the counterfactual prediction that buyers should make a constant payment each period regardless of the output they consume. Such a trading arrangement is certainly not typical of most purchases made with money in retail markets. However, we do not view this counterfactual prediction as a reductio-absurdum attack on using competitive search in monetary economics. Instead, we view it as a caution that one must be careful in modelling competitive search to generate sensible results. In particular, the presence of market makers is not an innocuous expositional device and should be used with great care or avoided entirely. Also, we view our result as a simple extreme case of a broader tendency in competitive search to make payments predictable to avoid idle money balances. Even without market makers, this tendency may manifest itself in more realistic ways as shown in $[2]$.

The rest of the paper is organized as follows. Section 2 describes the environment where buyers and sellers operate. Section 3 finds the competitive-search equilibrium that arises if market makers can charge differential fees to buyers and sellers. Section 4 compares this equilibrium to the one characterized by [4] where differential fees are absent. Section 5 concludes.

\footnotetext{
${ }^{3}$ In the absence of market makers, buyers cannot commit to make a payment when they fail to meet a seller. So, idle money balances are unavoidable.
} 


\section{Environment}

We use a special case of the environment advanced in [4] which we briefly summarize here. This environment is a modified version of the framework in [3]. ${ }^{4}$

In this environment, time is discrete, and the horizon is infinite. Each period consists of two subperiods to be called day and night. There is a single non-durable good which is traded in a frictionless and centralized market during the day, but it is traded in a decentralized market during the night. In the day market, everybody can produce and consume the good, but at the night market only a fraction of the population can produce the good, and the remaining fraction can consume it. The fraction of the population that can produce at night are called sellers, and the fraction of the population that can consume at night are called buyers. There is a continuum of buyers and sellers. The measure of buyers is exogenous and normalized to 1, and the measure of active sellers is endogenous and denoted $n_{t} \geq 0$. Sellers must incur a utility cost $k>0$ every night to enter the market. ${ }^{5}$

In this environment, there is a role for money to facilitate trade because at night there is a lack of double coincidence of wants, and all traders are anonymous. Money is an intrinsically useless, perfectly divisible, and storable asset. The money supply grows at a constant factor $\gamma$ such that $M_{t+1}=\gamma M_{t}$, where $M_{t}$ is the quantity of money per buyer, with the units of money called dollars. New money is injected via lump-sum transfers to buyers when they are in the centralized market.

The instantaneous utility of a buyer at date $t$ is:

$$
U^{b}\left(x_{t}, y_{t}, q_{t}\right)=v\left(x_{t}\right)-y_{t}+u\left(q_{t}\right)
$$

\footnotetext{
${ }^{4}$ In [3], where trading roles are not known ex-ante, competitive search leads to a gift exchange equilibrium even if market makers are not present.

${ }^{5}$ Following [4], the measure of potential sellers is assumed to be sufficiently large, so that in all equilibria we consider a fraction of sellers remains inactive at night.
} 
where $x_{t}$ and $y_{t}$ respectively are quantities consumed and produced during the day, and $q_{t}$ is the quantity consumed during the night. Likewise, the instantaneous utility of a seller is:

$$
U^{s}\left(x_{t}, y_{t}, q_{t}\right)=v\left(x_{t}\right)-y_{t}-c\left(q_{t}\right)
$$

The lifetime utilities of buyers and sellers are $E \sum_{t=0}^{\infty} \beta^{t} U^{h}\left(x_{t}, y_{t}, q_{t}\right)$, for $h=b$ and $s$, and $\beta$ is the one-period discount factor. We assume $\gamma>\beta$. The functions $v, u$, and $c$ are all continuously differentiable and increasing. The functions $v$ and $u$ are concave, while $c$ is convex. Moreover, $v(0)=u(0)=c(0)=c^{\prime}(0)=0$, and $u^{\prime}(0)=\infty$.

During the night, there are some agents called market makers who can open submarkets. To find a trading partner, buyers and sellers must enter one of these submarkets. In submarket $j$, the market maker charges buyers a fee $D_{t}^{b j}$ and sellers a fee $D_{t}^{s j}$. These fees can be negative, in which case the market maker pays a trader to enter the submarket. Entering a submarket $j$ involves a commitment to a particular trading offer $\left(q_{t}^{j}, d_{t}^{j}\right)$ posted ex-ante by the market maker. These trading offers specify that if a trading meeting occurs between a buyer and a seller, the seller will supply $q_{t}^{j}$ units of output, and the buyer will pay $d_{t}^{j}$ dollars.

Inside each submarket, buyers and sellers are randomly matched in pairs, and goods can only be exchanged in these matches. (The market maker cannot transfer goods directly from buyers to sellers.) Let $n_{t}^{j}$ be the ratio of sellers over buyers in submarket $j$. The probability that a buyer meets a seller is an increasing function of $n_{t}^{j}: \alpha_{t}^{b j}=\alpha\left(n_{t}^{j}\right)$. Likewise, the probability a seller meets a buyer is $\alpha_{t}^{s j}=\alpha\left(n_{t}^{j}\right) / n_{t}^{j}$. The restrictions we impose on $\alpha\left(n_{t}^{j}\right)$ are: $\alpha^{\prime}\left(n_{t}^{j}\right)>0, \alpha^{\prime \prime}\left(n_{t}^{j}\right)<0$, $\alpha\left(n_{t}^{j}\right) \leq \min \left\{1, n_{t}^{j}\right\}, \alpha(0)=0$, and $\alpha(\infty)=1$. As a result of these restrictions, the probability that a seller meets a buyers falls with $n_{t}^{j}$. For simplicity, we focus on stationary equilibria where real allocations are constant over time. The time subscript $t$ is omitted and we shorten $t+1$ to +1 in what follows. We also drop the superscript $j$ denoting a submarket whenever there is no possibility of confusion. 


\subsection{The Behavior of Buyers}

This subsection characterizes the optimal behavior of a buyer who plans to visit a submarket where buyers meet sellers with probability $\alpha^{b}$. In this submarket, $q$ units of output are exchanged for $d$ dollars. In addition, to enter the submarket the buyer must pay $D^{b}$ dollars.

A representative buyer that starts the morning with money balances $m_{0}^{b}$ faces the following budget constraint:

$$
x^{b}+m^{b} \phi=y^{b}+m_{0}^{b} \phi, \quad m^{b} \geq 0
$$

where $x^{b}$ and $y^{b}$ are respectively the consumption and the production of goods during the day, $m^{b}$ is the amount of money demanded, the price of the good traded during the day is normalized to 1 , and the price of money is $\phi$. The optimal choice of $\left\{x^{b}, y^{b}, m^{b}\right\}$ solves the following maximization program:

$$
\begin{aligned}
V^{b}\left(m_{0}^{b}\right)= & \max _{\left\{x^{b}, y^{b}, m^{b}\right\}} v\left(x^{b}\right)-y^{b}+\alpha^{b}\left[u(q)+\beta V_{+1}^{b}\left(m^{b}-D^{b}-d+\tau_{+1}\right)\right] \\
& +\left(1-\alpha^{b}\right) \beta V_{+1}^{b}\left(m^{b}-D^{b}+\tau_{+1}\right) .
\end{aligned}
$$

subject to (3) and $\max \left(D^{b}+d, D^{b}\right) \leq m^{b}$. The buyer must carry enough money to pay the entry fee to the submarket and the direct payment to a seller. The term $\tau_{+1}$ denotes the lump-sum transfer that all buyers receive from the government the next day.

The quasi-linearity of preferences implies that

$$
x^{b}=x^{*},
$$

where $x^{*}$ is implicitly defined by the equality $v^{\prime}\left(x^{*}\right)=1$. Also, as in [3], the quasi-linearity implies that the value function is affine:

$$
V^{b}\left(m_{0}^{b}\right)=\bar{v}^{b}+m_{0}^{b} \phi
$$


where $\bar{v}^{b}$ is independent from $m_{0}^{b}$. Substituting (3), (5), and (6) into (4), we obtain

$$
\begin{aligned}
V^{b}\left(m_{0}^{b}\right)= & v\left(x^{*}\right)-x^{*}+\beta\left(\bar{v}^{b}-D^{b} \phi_{+1}+\tau_{+1} \phi_{+1}\right)+m_{0}^{b} \phi \\
& +\max _{m^{b}}\left\{\alpha^{b}\left[u(q)-\beta d \phi_{+1}\right]-\beta m^{b} \phi_{+1}\left(\frac{\phi}{\beta \phi_{+1}}-1\right)\right\} .
\end{aligned}
$$

In a stationary equilibrium, ${ }^{6}$ the value of money $\phi$ declines at the same rate as the quantity of money increases. Hence, $\phi=\gamma \phi_{+1}$. The opportunity cost of holding money, to be denoted $i$, is

$$
i=\frac{\phi}{\beta \phi_{+1}}-1=\frac{\gamma-\beta}{\beta}
$$

Since $\gamma>\beta, i$ is strictly positive. Therefore, (7) implies that the buyer should not carry money balances above the maximum payment to be made, that is $m^{b}=\max \left(D^{b}+d, D^{b}, 0\right)$. Defining $z \equiv \beta d \phi_{+1}, Z^{b}=\beta D^{b} \phi_{+1}$, and $\hat{m}^{b}=\beta m^{b} \phi_{+1}$, we have that the utility of a buyer in a stationary equilibrium satisfies:

$$
V^{b}\left(m_{0}^{b}\right)=v\left(x^{*}\right)-x^{*}+\beta\left(\bar{v}^{b}+\tau_{+1} \phi_{+1}\right)+m_{0}^{b} \phi+\alpha^{b}[u(q)-z]-Z^{b}-i \hat{m}^{b}
$$

where

$$
\hat{m}^{b}=\max \left(Z^{b}+z, Z^{b}, 0\right)
$$

The last three terms in (9) constitute the expected surplus of a buyer for going to the search market for one night:

$$
S^{b}=\alpha^{b}[u(q)-z]-Z^{b}-i \hat{m}^{b}
$$

The term inside the square brackets is the consumer's surplus in a trading match, which is the difference between the utility from consuming $q$ units of output and the utility value of the payment. The last two terms are the entry fee into the submarket, and the opportunity cost of carrying money. Notice that (9) confirms that $V^{b}$ is affine as long as $q, d$, and $D^{b}$ are independent from $m_{0}^{b}$. The next two sections confirm that this independence holds.

\footnotetext{
${ }^{6}$ Our arguments should be robust to all equilibria with a positive opportunity cost of holding money.
} 


\subsection{The Behavior of Sellers}

This subsection characterizes the optimal behavior of a seller who plans to visit a submarket with an entry fee $D^{s}$ (possibly negative). In this submarket, the seller meets a buyer with probability $\alpha^{s}$ and in a trading match the seller exchanges $q$ units of output for $d$ dollars.

A representative seller who starts the morning with money balances $m_{0}^{s}$ faces a budget constraint analogous to (3) replacing the superscript $s$ denoting seller for $b$ :

$$
x^{s}+m^{s} \phi=y^{s}+m_{0}^{s} \phi, \quad m^{s} \geq 0
$$

The optimal choice of $\left\{x^{s}, y^{s}, m^{s}\right\}$ solves the following maximization program:

$$
V^{s}\left(m_{0}^{s}\right)=\max _{\left\{x^{s}, y^{s}, m^{s}\right\}} v\left(x^{s}\right)-y^{s}+\alpha^{s}\left[-c(q)+\beta V_{+1}^{s}\left(m^{s}-D^{s}+d\right)\right]+\left(1-\alpha^{s}\right) \beta V_{+1}^{s}\left(m^{s}-D^{s}\right)-k
$$

subject to $(12)$ and $\max \left(D^{s}-d, D^{s}\right) \leq m^{s}$.

The quasi-linearity of preferences implies that $x^{s}=x^{*}$, and $V^{s}\left(m_{0}^{s}\right)=\bar{v}^{s}+m_{0}^{s} \phi$. Using these equalities and the budget constraint (12), equation (13) simplifies into:

$$
\begin{aligned}
V^{s}\left(m_{0}^{s}\right)= & v\left(x^{*}\right)-x^{*}+\beta\left(\bar{v}^{s}-D^{s} \phi_{+1}\right)+m_{0}^{s} \phi \\
& +\max _{m^{s}}\left\{\alpha^{s}\left[-c(q)+\beta d \phi_{+1}\right]-\beta m^{s} \phi_{+1}\left(\frac{\phi}{\beta \phi_{+1}}-1\right)\right\}-k .
\end{aligned}
$$

Again since $\gamma>\beta$, the fraction $\phi /\left(\beta \phi_{+1}\right)$ is larger than one in a stationary equilibrium. Therefore, (14) implies that the seller should not carry money balances above the maximum possible payment, that is, $m^{s}=\max \left(D^{s}, D^{s}-d, 0\right)$. Defining $Z^{s}=\beta D^{s} \phi_{+1}, \hat{m}^{s}=\beta m^{s} \phi_{+1}$, we have that the utility of a seller in a stationary equilibrium satisfies

$$
V^{s}\left(m_{0}^{s}\right)=v\left(x^{*}\right)-x^{*}+\beta \bar{v}^{s}+m_{0}^{s} \phi+\alpha^{s}[z-c(q)]-Z^{s}-i \hat{m}^{s}-k,
$$

where $\hat{m}^{s}=\max \left(Z^{s}, Z^{s}-z, 0\right)$. The last four terms in (15) constitute the expected surplus of the 
seller for being active in the search market for one night:

$$
S^{s}=\alpha^{s}[z-c(q)]-Z^{s}-i \hat{m}^{s}-k .
$$

The term inside square brackets is the seller's surplus in a trading match. The last three terms are the entry fee into the submarket, the opportunity cost of carrying money to the search market, and the utility cost of searching for one night. As long as $S^{s}>0$, the seller is strictly better off by entering the search market. If $S^{s}<0$, the seller chooses not to enter the search market. At $S^{s}=0$, the seller is indifferent between entering the search market or not.

\section{Competitive Search with Differential Fees}

This subsection characterizes the competitive-search equilibrium along the same lines as in [4] with the difference that we relax the assumption that market makers cannot charge differential fees to buyers and sellers to enter their submarkets.

Let $\omega^{j}=\left(Z^{b j}, Z^{s j}, q^{j}, z^{j}, n^{j}\right)$ be the vector that characterizes an active submarket, and $I$ be the set of indices of the submarkets that are active. A competitive-search equilibrium is a set $\left\{S^{b}, S^{s}, \omega^{j}\right\}_{j \in I}$ that satisfies the following 5 conditions:

1. All buyers attain the same expected surplus $S^{b}$ in all active submarkets.

2. All sellers attain the same expected surplus $S^{s}$ in all active submarkets. This expected surplus must be zero: $S^{s}=0$.

3. In all submarkets, the expected ratio of sellers over buyers is equal to the actual ratio $n^{j}$.

4. In all submarkets, $\omega^{j}$ maximizes the profits of the market maker organizing $j, Z^{b j}+n^{j} Z^{s j}$, taking $S^{b}$ and $S^{s}$ as given.

5. The market makers in all active submarkets earn zero profits: $Z^{b j}+n^{j} Z^{s j}=0$ for all $j \in I$. 
The motivation of these conditions of equilibrium is the following: Since all buyers are exante homogenous, their freedom to choose the submarket where they search implies that all active submarkets must provide them with the same expected surplus (condition 1). Similarly, a perfectly elastic supply of sellers free to enter any one of the active submarkets implies that in equilibrium the expected surplus of a seller must be zero (condition 2). Rational expectations implies condition 3. The objective of market makers is to maximize profits. Strategically, a potential market maker realizes that by charging fees $Z^{b j}$ and $Z^{s j}$ and by posting a trading offer $\left(q^{j}, z^{j}\right)$ the submarket created will either be inactive, or the ratio $n^{j}$ will adjust endogenously so that the buyers and sellers visiting the submarket attain the expected surpluses $S^{b}$ and $S^{s}$. Since there are many potential market makers and a continuum of buyers and sellers, each market maker takes $S^{b}$ and $S^{s}$ as given (condition 4). Finally, competition among all potential market makers drives equilibrium profits to zero (condition 5), which does not imply that the fees paid by buyers and sellers are necessarily zero. With the ability to charge differential fees, the market maker may impose positive fees on buyers to finance transfers to sellers, or vice versa.

To characterize a competitive-search equilibrium, it is convenient to use a dual formulation of condition 4. Since the profits of the market maker and the expected surpluses of buyers and sellers are monotonic in $Z^{b}$ and $Z^{s}$, condition 4 is equivalent to the maximization of $S^{b}$ as defined in (11) subject to $S^{s}$ and the optimized profits attained by the market maker. Consequently, collecting the equilibrium conditions 1 to 5 , the vector $\omega$ in an active submarket must solve the following maximization program (the superscript denoting that the submarket is dropped since all variables refer to the same submarket):

$$
S^{b}=\max _{\left(Z^{b}, Z^{s}, q, z, n\right)} \alpha(n)[u(q)-z]-Z^{b}-i \hat{m}^{b}
$$

subject to 


$$
\begin{gathered}
\frac{\alpha(n)}{n}[z-c(q)]-Z^{s}-i \hat{m}^{s}=k . \\
\hat{m}^{b}=\max \left(Z^{b}, Z^{b}+z\right), \\
\hat{m}^{s}=\max \left(Z^{s}, Z^{s}-z, 0\right), \text { and } \\
Z^{b}=-Z^{s} n .
\end{gathered}
$$

In (19), we have dropped the non-negativity constraint on $\hat{m}^{b}$ because the other constraints ensure that it holds. To see this, (18) together with (20) and $k n+\alpha(n) c(q)>0$ implies that $-n Z^{s}+$ $\alpha(n) z>0$. This inequality, combined with (21) and (10), implies $\hat{m}^{b}>0$. Intuitively, we see that sellers can only be remunerated if $\hat{m}^{b}$ is positive.

The difficulty in solving (17) to (21) is to keep track of the many possibilities offered by the maximum functions in (19) and (20). To deal with this difficulty, we establish the following result:

Lemma 1 Let $S^{b}(\omega)$ be a function mapping the set of potential submarkets $\Omega$ onto $S^{b}$. If $\omega_{1}=$ $\left(Z_{1}^{b}, Z_{1}^{s}, q_{1}, z_{1}, n_{1}\right)$ is in $\Omega$ and satisfies the constraints (18) to (21), then the vector $\omega_{2}=\left(Z_{2}^{b}, Z_{2}^{s}, q_{1}, z_{2}, n_{1}\right)$ with $z_{2}=0$ and $Z_{2}^{b}=-n Z_{2}^{s}=k n_{1}+\alpha\left(n_{1}\right) c\left(q_{1}\right)$ also satisfies the constraints (18) to (21) and

$$
S^{b}\left(Z_{1}^{b}, Z_{1}^{s}, q_{1}, z_{1}, n_{1}\right) \leq S^{b}\left(Z_{2}^{b}, Z_{2}^{s}, q_{1}, z_{2}, n_{1}\right)
$$

The inequality (22) is strict if $\alpha\left(n_{1}\right)<1$ and $z_{1}>0$, or $\alpha\left(n_{1}\right)>0$ and $z_{1}<0$.

Proof: A direct check shows that $\omega_{2}$ satisfies (18) to (21) if $\omega_{1}$ does so. Combining (11) with (18) and (21), we obtain:

$$
S^{b}\left(Z^{b}, Z^{s}, q, z, n\right)=\alpha(n)[u(q)-c(q)]-n k-i\left(\hat{m}^{b}+n \hat{m}^{s}\right)
$$

Therefore, using subscripts 1 and 2 on $\hat{m}^{b}$ and $\hat{m}^{s}$ to denote their values with $\omega_{1}$ and $\omega_{2}$ respectively, 
we have:

$$
\begin{aligned}
S^{b}\left(Z_{2}^{b}, Z_{2}^{s}, q_{1}, 0, n_{1}\right)-S^{b}\left(Z_{1}^{b}, Z_{1}^{s}, q_{1}, z_{1}, n_{1}\right) & =i\left[\hat{m}_{1}^{b}+n_{1} \hat{m}_{1}^{s}-\left(\hat{m}_{2}^{b}+n_{1} \hat{m}_{2}^{s}\right)\right] \\
& \geq i\left[Z_{1}^{b}+\max \left(z_{1}, 0\right)-Z_{2}^{b}\right] \\
& \geq i\left[-n_{1} Z_{1}^{s}+\alpha\left(n_{1}\right) z_{1}-k n_{1}-\alpha\left(n_{1}\right) c\left(q_{1}\right)\right] \\
& \geq 0
\end{aligned}
$$

Equation (24) follows from (23). Inequality (25) is implied by (19) together with $z_{2}=0, \hat{m}_{1}^{s} \geq 0$, and $\hat{m}_{2}^{s}=0$. Inequality (26) results from (21), the definition of $Z_{2}^{b}$, and $\alpha\left(n_{1}\right) \in[0,1]$. Inequality (26) is strict if $\alpha\left(n_{1}\right)<1$ and $z_{1}>0$, or $\alpha\left(n_{1}\right)>0$ and $z_{1}<0$. Finally, (27) follows from (18) and $\hat{m}_{1}^{s} \geq 0$

Since Lemma 1 applies to all vectors in $\Omega$, including the solutions to program (17) to (21), all submarkets active in an equilibrium where $\alpha(n) \in(0,1)$ must have $z=0$. Intuitively, as long as $\alpha(n) \in(0,1)$, using the market maker to transfer money from buyers to sellers eliminates idle money balances, so that it minimizes the opportunity cost of money holdings. If an active submarket has $\alpha(n)=1$, then the buyer pays $Z^{b}+z$ for sure, and the expected remuneration of a seller is $\left(Z^{b}+z\right) / n$. Therefore, the breakdown between $Z^{b}$ and $z$ is undetermined but irrelevant.

Using Lemma 1, programs (17) to (21) simplify into

$$
\max _{(q, n)} \alpha(n)[u(q)-c(q)]-k n-i[\alpha(n) c(q)+k n]
$$

The first-order conditions that characterize $q$ and $n$ are:

$$
\begin{gathered}
\frac{u^{\prime}(q)}{c^{\prime}(q)}=1+i \\
\alpha^{\prime}(n)\left[\frac{u(q)}{1+i}-c(q)\right]=k .
\end{gathered}
$$

As a necessary condition for $n>0$, we assume $k<u\left(q^{*}\right)-c\left(q^{*}\right)$, where $q^{*}$ is the solution to $u^{\prime}\left(q^{*}\right)=c^{\prime}\left(q^{*}\right)$ 
Defining welfare per period as $W=\alpha(n)[u(q)-c(q)]-n k$, this system implies the following comparative statics:

$$
\frac{d q}{d i}<0, \frac{d n}{d i}<0, \text { and } \frac{d W}{d i}<0
$$

An increase in inflation represents an implicit tax on the goods purchased with money. As a result, the market responds by cutting both the number of sellers active at night and the output they offer. Since welfare is an increasing function of both $q$ and $n$, inflation implies welfare losses.

Up until now, $-Z^{s}$ has been assumed to be a lump-sum payment from the market maker to the seller conditional only upon the seller's entry into the submarket. This is a convenient simplification, but it is not necessary to solve (17) to (21). The payment sellers receive could be randomized or made conditional on trading with a buyer. As long as the handouts are adjusted so that sellers receive the same expected payment, they will attain the same expected surplus. Moreover, the optimal $q$ and $n$ would still be given by (29) and (30). To avoid idle money balances, the amounts paid by buyers should be predictable, but it is not essential if the payments received by sellers are predictable or not.

\section{Equilibrium without Differential Fees}

This section briefly compares the competitive-search equilibrium in the previous section with the one characterized in [4] without the possibility of differential entry fees. If the market maker cannot distinguish between buyers and sellers, we have that the fees charged to all traders must be the same: $Z^{b}=Z^{s}$. This equality combined with the zero-profits constraint (21) implies ${ }^{7}$

$$
Z^{b}=Z^{s}=0
$$

The absence of differential fees adds the extra constraint (31) to the program (17) to (21) that

\footnotetext{
${ }^{7}$ As remarked in [4], (31) also follows from $Z^{b} \geq 0$ and $Z^{s} \geq 0$.
} 
characterizes a competitive-search equilibrium. With this extra constraint, this program simplifies into

$$
\max _{(q, z, n)} \alpha(n)[u(q)-z]-i z
$$

subject to

$$
\frac{\alpha(n)}{n}[z-c(q)]=k
$$

The welfare comparison between the equilibria that result with and without differential fees is straightforward. In both cases, the expected surplus of sellers in equilibrium is zero, and market makers earn zero profits. The expected surplus of buyers is the objective of the two programs we used to characterize a competitive equilibrium. Since (32) to (33) are equivalent to (17) to (21) with the added constraint (31), the expected surplus of buyers with differential fees must be at least the expected surplus of buyers without them. Moreover, if $\alpha(n)<1$ and $i>0$, then Lemma 1 implies that buyers are strictly better off with differential fees. In this instance, market makers are not just an expositional device but also play a fundamental role in the economy.

The first order conditions of program (32) to (33) that characterize $q$ and $n$ are

$$
\begin{gathered}
\frac{u^{\prime}(q)}{c^{\prime}(q)}=1+\frac{i}{\alpha(n)}, \text { and } \\
\alpha^{\prime}(n)[u(q)-c(q)]=k\left\{1+\left[1-\frac{\alpha^{\prime}(n) n}{\alpha(n)}\right] \frac{i}{\alpha(n)}\right\}
\end{gathered}
$$

Comparing (29), (30) with (34) and (35), it is clear that if $i=0$, the equilibrium values of $q$ and $n$ are identical with and without differential fees, so that the two equilibria coincide at the Friedman rule. However, if $i>0$ and $\alpha(n)<1$, the quantity traded $q$ is higher with differential fees because the LHS of (34) is a decreasing function of $q$. The number of sellers $n$ cannot be unambiguously compared across the two equilibria without further assumptions. The welfare cost of inflation without differential fees exceeds the welfare cost of inflation with differential fees because 
the two equilibria coincide at $i=0$ but, as discussed above, welfare is lower without differential fees if $i>0$.

\section{Conclusion}

A positive opportunity cost of holding money implies that the trading arrangements in a competitivesearch equilibrium tend to make payments predictable to reduce the demand for money. By eliminating the restriction in [4] that entry fees must be either non-negative or identical for buyers and sellers, we show that this tendency leads to the following result. In an equilibrium with frictional matching, buyers pay only an entry fee to the market maker, so that they know exactly the amount of money they are going to spend in the search market. This mechanism eliminates the carrying of idle money balances. The charging of an entry fee is atypical of most purchases made with money. Hence, this counterfactual result acts as a caution against using market makers for formulating competitive search in monetary economies.

The tendency towards predictable payments goes well beyond the simple trading arrangement analyzed in this model. Even if market makers do not exist or cannot charge differential fees, predictable payments do reduce the opportunity cost of carrying money balances. The mechanism used to make payments predictable depends on the instruments available. For example, [2] provides a model where there are no market makers to charge differential fees, but buyers still experience observable idiosyncratic shocks after matching with a seller. In that model, the tendency to make payments predictable takes the form of cross subsidies across buyer types. If preference shocks are observable and individual rationality constraints are not binding, buyers pay again a single flat fee in equilibrium. However, in general the smoothing of the flow of payments is not complete, so payments increase with the quantities purchased. 


\section{References}

[1] A. Berentsen, G. Camera, C. Waller, Money, credit, and banking, manuscript Univ. of Basel, 2004 .

[2] M. Faig, B. Jerez, Inflation, prices, and information in competitive search, manuscript Univ. of Toronto, 2005.

[3] R. Lagos, R. Wright, A unified framework for monetary theory and policy analysis, J. Polit. Economy, 113 (2005), 463-484.

[4] G. Rocheteau, R. Wright, Money in search equilibrium, in competitive equilibrium, and in competitive search equilibrium, Econometrica 73 (2005), 175-203. 